\title{
CROSSLINKED CARBOXYMETHYL CELLULOSE-SiO2 HYDROGELS FABRICATION: COMPOSITION AND THERMAL STABILITY TOWARDS BIOMEDICAL APPLICATIONS
}

\author{
David Patiño Ruíz ${ }^{1 *}$ \\ ${ }^{1}$ Universidad de Cartagena. Cartagena de Indias, Colombia \\ *Autor de correspondencia: dpatinor@unicartagena.edu.co \\ Recibido 29 Agosto 2020; Aceptado 9 Octubre 2020
}

\begin{abstract}
Novel and innovative materials for biomedical and pharmaceutical applications have to consider several factors during their fabrication, such as the material composition and thermal stability, aiming to establish the promising physicochemical properties towards efficient and controlled drug release systems. In this study, carboxymethyl cellulose (CMC) hydrogels are prepared by incorporating silica dioxide (SiO2) nanoparticles previously modified with primary amine (-NH2) functional groups, aiming to evaluate the chemical composition and to improve the thermal efficiency. The carbodiimide chemistry method is performed to promote the crosslinking of the CMC structure through the formation of amide bonds from the activation of carboxyl $(\mathrm{C}=\mathrm{O})$ groups and further covalent binding with - $\mathrm{NH} 2$ groups. The morphology information displays high dispersed SiO2 nanoparticles with a smooth surface, regular shape, and an average particle size of $104 \mathrm{~nm}$. The material composition and thermal stability are evaluated using the Fourier transform infrared spectroscopy and thermogravimetric analysis to establish a preliminary overview of a functional hydrogel for biomedical and pharmaceutical applications. The formation of amide bonds is confirmed indicating the successful crosslinking of the CMC structure with SiO2-NH2 nanoparticles, which is attributed to the activation of the $\mathrm{C}=\mathrm{O}$ groups and its strong affinity to the $-\mathrm{NH} 2$ groups. This interaction enhanced the thermal stability of the crosslinked CMC-SiO2 hydrogels up to $469^{\circ} \mathrm{C}$ which was the last decomposition event, outstanding the contribution of major content of SiO2-NH2 nanoparticles. These results suggest a suitable procedure for the fabrication of crosslinked CMC-SiO2 hydrogels as novel materials with promising physicochemical properties, which can contribute to the biomedical and pharmaceutical fields in controlled drug release and delivery systems.
\end{abstract}

Keywords: Carboxymethyl cellulose hydrogel; silica dioxide nanoparticles; amine functionalization; carbodiimide crosslinker chemistry; material composition; thermal stability; biomedicine

\section{FABRICACIÓN DE HIDROGELES ENTRECRUZADOS DE CARBOXIMETIL CELULOSA-SiO2: COMPOSICIÓN Y ESTABILIDAD TÉRMICA HACIA APLICACIONES BIOMÉDICAS}

Resumen - Nuevos e innovadores materiales para aplicaciones biomédicas y farmacéuticas deben considerar factores como la composición y la estabilidad térmica para establecer las propiedades fisicoquímicas adecuadas para sistemas eficientes de liberación controlada de fármacos. En este estudio, hidrogeles de carboximetilcelulosa (CMC) son preparados incorporando nanopartículas de dióxido de sílice (SiO2) previamente modificadas con grupos de aminas primarias (-NH2), buscando evaluar 
la composición química y mejorar la estabilidad térmica. El método de carbodiimidas es utilizado para promover el entrecruzamiento de la CMC con la formación de enlaces amidas a partir grupos carboxilo $(C=O)$ activados y su posterior enlace con grupos -NH2. La información morfológica muestra nanopartículas de SiO2 dispersas con superficie lisa, forma regular, y diámetro promedio de $104 \mathrm{~nm}$. La composición del material y la estabilidad térmica son evaluadas usando la espectroscopia infrarroja de la transformada de Fourier y el análisis termogravimétrico para establecer una perspectiva preliminar de hidrogeles funcionales para aplicaciones biomédicas y farmacéuticas. La formación de enlaces amidas es confirmado indicando el entrecruzamiento exitoso de la estructura de la CMC con nanopartículas de SiO2-NH2, el cual es atribuido a la activación de los grupos $\mathrm{C}=\mathrm{O}$ y su fuerte afinidad a los grupos -NH2. Esta interacción mejoró la estabilidad térmica de los hidrogeles entrecruzados de CMC-SiO2 hasta $469^{\circ} \mathrm{C}$ la cual fue el último evento de descomposición, resaltando la contribución de una mayor presencia de nanopartículas de SiO2-NH2. Estos resultados sugieren un adecuado proceso de fabricación de hidrogeles entrecruzados de CMC-SiO2 como material novedoso con propiedades fisicoquímicas prometedoras, permitiendo contribuir en el campo biomédico y farmacéutico en sistemas de administración controlada de fármacos.

Palabras clave: Hidrogel de carboximetilcelulosa; nanopartículas de dióxido de sílice; funcionalización con aminas; entrecruzamiento con química de carbodiimida; composición del material; estabilidad térmica; biomedicina.

\section{Introduction}

In recent years, nanotechnology has been focusing on the development of innovative nanomaterials with exceptional physicochemical properties for a wide number of applications, outstanding the biomedicine and pharmaceutical fields(Tang et al., 2020).Among these nanomaterials, the silica dioxide (SiO2) nanoparticles are extensively explored due to the advantages offered by their biocompatibility, chemical, and enzymatical stability, reactive surface area, environmentally friendly, and good cost-effectiveness (Abeer et al., 2020). The SiO2 nanoparticles are synthesized through different physical and chemical methods, which is highlighted the Stöber method due to its simplicity and effectiveness. However, the presence of silanol $(\mathrm{Si}-\mathrm{OH})$ groups on the surface after the synthesis represent a challenge, reducing the advantages of using this type of nanoparticles (Sepulveda et al., 2020). This can be solved by functionalizing the surface of the $\mathrm{SiO} 2$ nanoparticles using different functional groups, such as primary amines (NH2), allowing also to increase the selectivity and affinity (Mahmoodi, Khorramfar, \& Najafi, 2011).

Also, biopolymers are being studied along with the nanomaterials for developing and designing different drug delivery systems, in which the combination provides superior characteristics, such as non-toxicity, biodegradability, and high loading cargo and sustained release (Gholamali \& Yadollahi, 2020). Carboxymethyl cellulose (CMC) is a promising example of these explored biopolymers and has proven to be efficient in therapeutic systems for biomedical and pharmaceutical applications (Rao et al., 2018). These CMC biopolymers have been explored in industries and academia for their promising physicochemical properties, including hydrophilicity, non-toxicity, and pH-sensitivity (Javanbakht \& Shaabani, 2019). The ability to hydrogel-forming using CMC is mainly attributed to the ionic nature and a large amount of carboxyl $(\mathrm{C}=\mathrm{O})$ and hydroxyl $(-\mathrm{OH})$ groups in the structure (Jeong, Kim, Kim, \& Jung, 2020).However, a few but important limitations, such as the mechanical, thermal, and chemical stability, need to be addressed in the CMC hydrogels to compete with synthetic and non-biodegradable polymers(Shahbazi, Ahmadi, Seif, \& Rajabzadeh, 2016).

IPSA SCIENTIA - Vol. 5 No $1-2020$ 
Physical, chemical (Lin et al., 2020), and enzymatic crosslinking methods arose to overcome the mentioned limitation in the CMC hydrogels formation, improving their physicochemical properties (Zhong et al., 2019). Among the crosslinking agents, citric acid, polyacrylamide, antibacterial Propolis honey, polyethylene glycol (Kanikireddy, Varaprasad, Jayaramudu, Karthikeyan \& Sadiku, 2020), glutaraldehyde, formaldehyde, carbodiimide (Jiang et al., 2016), calcium, and aluminum have been widely explored(Mahmoud, Abdou, Sobhy \& Fekry, 2017).Although the crosslinking of CMC hydrogel represent a good alternative, there are still challenges regarding the biocompatibility (Jiang et al., 2016), swelling (Jeong et al., 2020), and drug release (Kadry, 2019), which reports suggest their decreasing when using crosslinking agents. Carbodiimide crosslinker chemistry has been reported to be suitable for the hydrogel formation through the covalent binding between $\mathrm{NH} 2$ and $\mathrm{C}=\mathrm{O}$ groups, resulting in an amide crosslinked bonds in the polymer's structure, including poly (dimethylsiloxane) (Mapkar, Iyer, \& Coleman, 2009), and $\beta$-cyclodextrin (Tang et al., 2020).

This study reports the synthesis of $\mathrm{SiO} 2$ nanoparticles using the Stöber method, and the surface modification with primary -NH2 functional groups. These SiO2-NH2 nanoparticles were used for the first time, during the formation of CMC hydrogels via the carbodiimide crosslinker chemistry method. This study aims to evaluate the chemical composition and thermal stability of the resulting CMC hydrogels compared to similarly reported CMC hydrogels using other crosslinking agents. In this method, amides bonds were formed from the activation of $\mathrm{C}=\mathrm{O}$ groups in the $\mathrm{CMC}$ structure and the further binding with $\mathrm{NH} 2$ groups grafter on the surface of the $\mathrm{SiO} 2$ nanoparticles. The material composition was corroborated using the Fourier transform infrared (FTIR) spectroscopy, allowing to identify the successful formation of amide bonds. Whereas the thermogravimetric analysis (TGA) confirmed the high thermal stability due to the presence of uniform and spherical $\mathrm{SiO} 2$ nanoparticles. These results are promising for the preparation of crosslinked CMC-SiO2 hydrogels with enhanced physicochemical properties, aiming to contribute with a suitable biomaterial for applications in the biomedicine and pharmaceutical fields as an efficient and controlled drug release system.

\section{Experimental Methods}

\section{Materials}

Carboxymethyl cellulose sodium salt (CMC), tetraethyl orthosilicate (TEOS, 98\%), dimethyl sulfoxide (DMSO, 99\%), and (3-Aminopropyl)triethoxysilane (APTES, 98\%) were acquired from Alfa Aesar by Thermo Fisher Scientific. Ammonium hydroxide $\left(\mathrm{NH}_{4} \mathrm{OH}, 30 \%\right)$ and absolute ethanol were purchased from Merck. 1-Ethyl-3-(3-dimethylaminopropyl) carbodiimide (EDC), N-Hydroxysuccimide (NHS, 98\%), acetic acid (99\%), and nitric acid $\left(\mathrm{HNO}_{3}, 70 \%\right)$ were acquired from Sigma-Aldrich. Distilled water and deionized water were used in all the experiments.

\section{Synthesis of $\mathrm{SiO}_{2}$ nanoparticles}

The $\mathrm{SiO}_{2}$ nanoparticles were synthesized via the Stöber method consisted of the hydrolysis/condensation using the TEOS precursor(Sepulveda et al., 2020). Initially, $1.1 \mathrm{~mL}$ of TEOS was added into $50 \mathrm{~mL}$ of absolute ethanol followed by sonication at room temperature for $10 \mathrm{~min}$. Afterward, the hydrolysis of TEOS was carried out by adding $1.53 \mathrm{~mL}$ of distilled water dropwise into the previous solution and left to react for $5 \mathrm{~min}$ in the ultrasound bath at room temperature. The condensation and further nucleation were IPSA SCIENTIA - Vol. 5 No $1-2020$ 
promoted using $5.71 \mathrm{~mL}$ of $\mathrm{NH}_{4} \mathrm{OH}$ as the catalyst, allowing to react for another 15 min at the same operating conditions. After completing the reaction time, the solution was taken out of the ultrasound and left for solidification during $1 \mathrm{~h}$, consisting of the stable growth of the colloids. The resulting $\mathrm{SiO}_{2}$ nanoparticles were collected by centrifugation at 15000 g-force and room temperature for $15 \mathrm{~min}$ and then washed with distilled water and absolute ethanol to eliminate remaining TEOS and other impurities. Finally, the $\mathrm{SiO} 2$ nanoparticles were dried in a conventional oven at $70^{\circ} \mathrm{C}$ for $2 \mathrm{~h}$.

\section{Amine functionalization of $\mathrm{SiO}_{2}$ nanoparticles}

The surface of the $\mathrm{SiO}_{2}$ nanoparticles was modified by grafting amine $\left(-\mathrm{NH}_{2}\right)$ functional groups from APTES molecules(Z. Zhang et al., 2018).Here, $1.5 \mathrm{~g}$ of $\mathrm{SiO}_{2}$ nanoparticles were suspended in $80 \mathrm{~mL}$ of DMSO using an ultrasound bath and then vigorous stirring. Afterward, $5 \mathrm{~mL}$ of APTES, $1.25 \mathrm{~mL}$ of distilled water, and $0.1 \mathrm{~mL}$ of acetic acid were added dropwiseand the solution was left to react for $72 \mathrm{~h}$ at room temperature. The $\mathrm{SiO}_{2}-\mathrm{NH}_{2}$ nanoparticles were separated from the solution centrifuging at $15000 \mathrm{~g}-$ force and room temperature for $15 \mathrm{~min}$ followed by washes with distilled water and ethanol. Then, 0.1 or $0.5 \mathrm{~g}$ of the as-synthesized $\mathrm{SiO}_{2}-\mathrm{NH}_{2}$ nanoparticles were dispersed in $10 \mathrm{~mL}$ of deionized water using an ultrasound bath for 15 min and the $\mathrm{pH}$ was adjusted to 4 adding drops of a $2 \mathrm{M} \mathrm{HNO}_{3}$ solution. The suspension was stored at $4^{\circ} \mathrm{C}$ for further crosslinking with CMC.

\section{Preparation of crosslinked $\mathrm{CMC}^{-\mathrm{SiO}_{2}}$ hydrogel}

The crosslinked CMC-SiO ${ }_{2}$ hydrogel was prepared through carbodiimide crosslinker chemistry between carboxylic acid and primary amine functional groups(Tang et al., 2020). Initially, the hydrogel was prepared by adding $0.1 \mathrm{~g}$ of CMC sodium salt in $7.5 \mathrm{~mL}$ of deionized water under $125 \mathrm{rpm}$ of stirring at room temperature. Once the solution is homogenized, the $\mathrm{pH}$ was adjusted to 5 using drops of a $0.1 \mathrm{M}$ $\mathrm{NaOH}$ solution. Then, the carboxyl groups of the CMC sodium salt were activated adding $12.5 \mathrm{mg}$ of EDC and $7.5 \mathrm{mg}$ of NHS, keeping the same operating conditions. Afterward, the formation of amide bonds was performed adding the $\mathrm{SiO}_{2}-\mathrm{NH}_{2}$ nanoparticles suspension into the previous hydrogel solution, which was left to react at $125 \mathrm{rpm}$ and room temperature for $48 \mathrm{~h}$. Finally, the crosslinked $\mathrm{CMC}-\mathrm{SiO}_{2}$ hydrogel was dried using an electric oven at $38^{\circ} \mathrm{C}$ for $7 \mathrm{~h}$.

\section{Characterizations}

The morphology of the $\mathrm{CMC}$ and $\mathrm{SiO} 2$ nanoparticles was investigated using a scanning electron microscope (SEM) QUANTA FEG 650 with an acceleration voltage of $7 \mathrm{kV}$. The identification of the functional groups and the crosslinked structure was performed using the Fourier transform infrared (FTIR) spectroscopy in an IR Affinity Shimadzu S/N A213749 equipment. The KBr dispersion method was used in a wave number range between 4000 and $400 \mathrm{~cm}^{-1}$ at room temperature for $10 \mathrm{~min}$. The thermogravimetric analysis (TGA) and derivative thermogravimetric (DTG) curve were performed in a TA Instruments SDT Q600 using a $100 \mathrm{~mL} / \mathrm{min}$ airflow in the temperature range of 26 and $600^{\circ} \mathrm{C}$ with a heating ramp of $10^{\circ} \mathrm{C} / \mathrm{min}$. 


\section{Results and Discussion}

The scanning electronic microscopy (SEM) was used to evaluate the morphology information of the assynthesized $\mathrm{SiO}_{2}$ nanoparticles. According to Figure 1, the $\mathrm{SiO}_{2}$ nanoparticles exhibit a regular smooth surface and sphere shape, which is attributed to the controlled hydrolysis/condensation procedure of TEOS precursor.Although some nanoparticles possess irregular shape, it can be stated that the $\mathrm{SiO}_{2}$ nanoparticles are regular with an average particle size of $104 \pm 12 \mathrm{~nm}$ as seen in Figure 2. Here, the solidification stage during $\mathrm{SiO}_{2}$ nanoparticles synthesis plays an important role since it allows controlling the particle size, and it has been reported that the longer is the solidification stage the larger is the particle size. Additionally, no agglomeration was noted in the SEM image allowing the confirm the high dispersion of the $\mathrm{SiO}_{2}$ nanoparticles. This is mainly attributed to the in-situ surface functionalization of the $\mathrm{SiO}_{2}$ nanoparticles with hydroxyl $(-\mathrm{OH})$ groups during the condensation of the silica matrix, which is typical for this nucleation method. The high dispersion of $\mathrm{SiO}_{2}$ nanoparticles represents a suitable feature when applying in the biomedicine field, which is used as nanoplatforms to bind different molecules for cell targeting (Giner-Casares, Henriksen-Lacey, Coronado-Puchau, \& Liz-Marzán, 2016), and drug delivery(Lee et al., 2020).

Figure 1. SEM image of $\mathrm{SiO}_{2}$ nanoparticles synthesized via the Stöber method

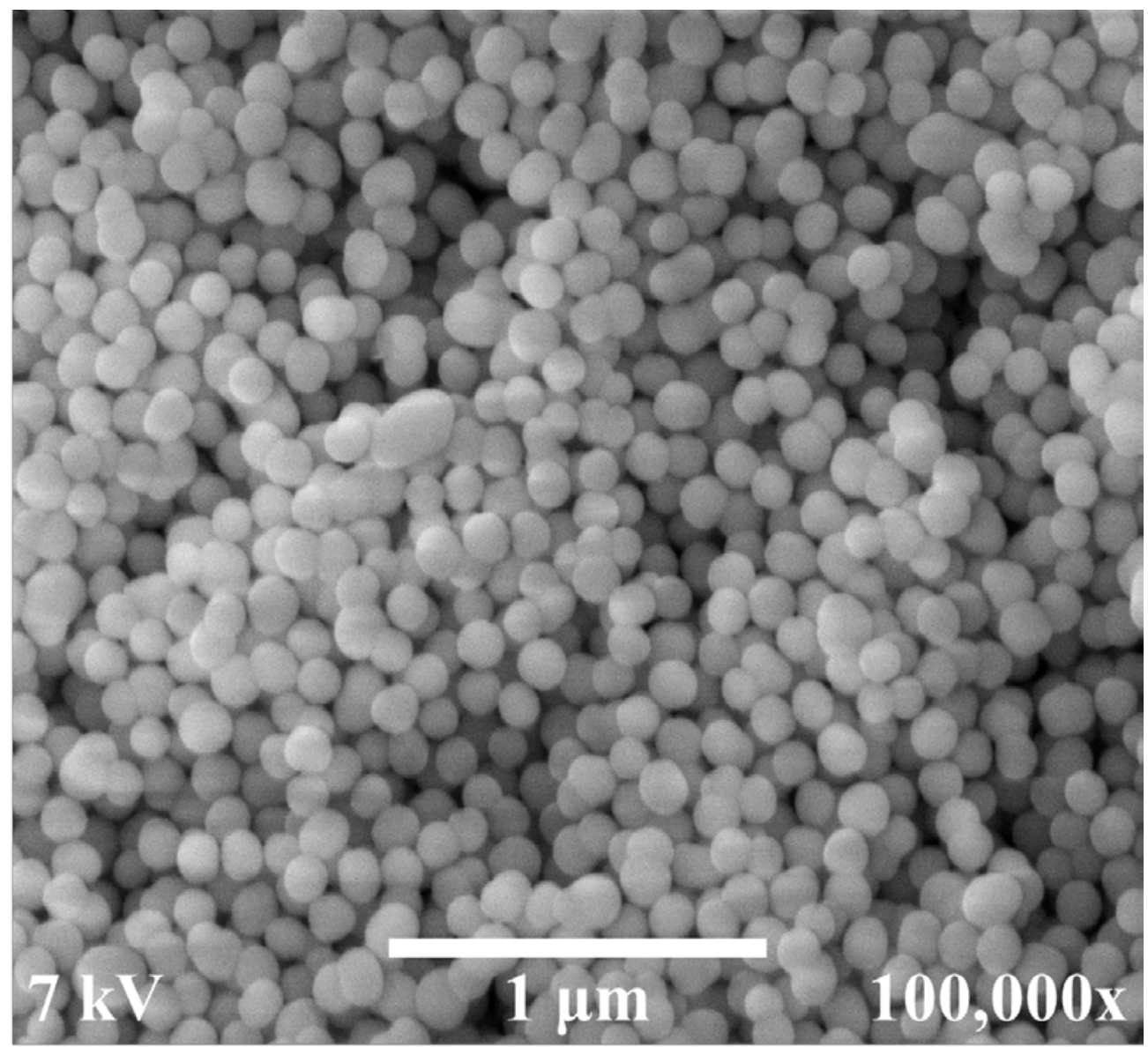

IPSA SCIENTIA - Vol. 5 No $1-2020$ 
Crosslinked carboxymethyl cellulose-SiO2 hydrogels fabrication: Composition and thermal stability towards biomedical applications

Source: own elaboration (2020)

Figure 2. $\mathrm{SiO}_{2}$ nanoparticles size distribution

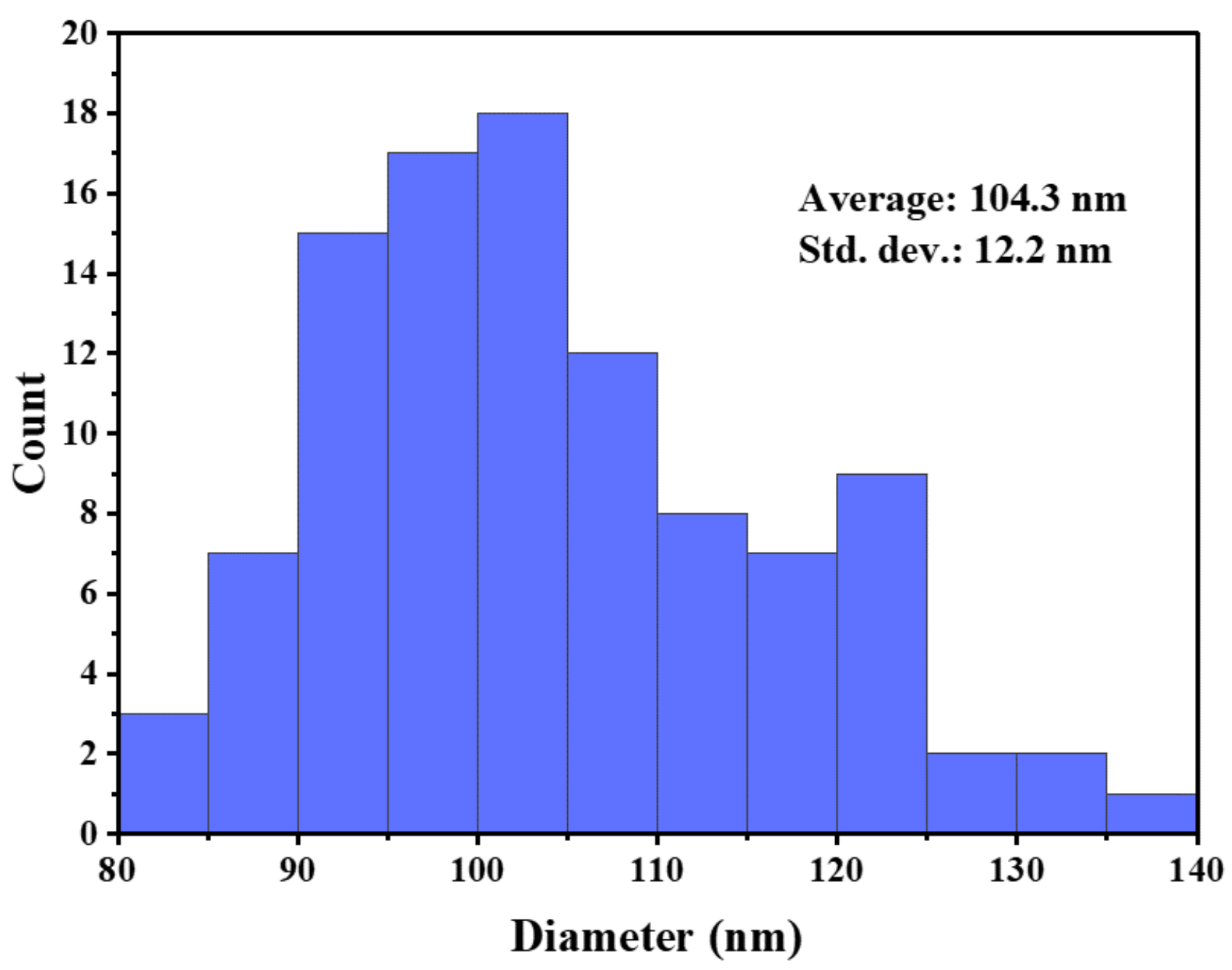

Source: own elaboration (2020)

The main functional groups of the crosslinked $\mathrm{CMC}-\mathrm{SiO}_{2}$ hydrogels were determined in the Fourier transform infrared (FTIR) spectra shown in Figure 3. Here, hydroxyl, carboxyl, and amine functional groups were identified after performing the carbodiimide crosslinker chemistry and using EDC and NHS. The intense and broadband between 3700 and $2500 \mathrm{~cm}^{-1}$ corresponds to the stretching vibrations of -OH groups. This broadband appeared due to the large number of -OH groups composing the CMC structure, which was highlighted a specifically centered peak around $3000 \mathrm{~cm}^{-1}$ ascribed to the carboxylic acid content (Zhu, Bao, Wei, Ma, \& Kong, 2016). In addition to this peak, high intensity but sharper peak located between 1440 and $1395 \mathrm{~cm}^{-1}$ was also related to the presence of the carboxylic acid content widely available in the CMC structure. A strong peak was noted at around $1640 \mathrm{~cm}^{-1}$ attributed to the presence of $\mathrm{C}=\mathrm{O}$ (Kamel, El-Gendy, Hassan, El-Sakhawy, \& Kelnar, 2020), and -NH bonds from the secondary amides (Rao et al., 2018), that were formed during the carbodiimide crosslinker chemistry (see Figure 4).

IPSA SCIENTIA - Vol. 5 No $1-2020$ 
Figure 3. Fourier transform infrared (FTIR) spectra for the identification of the functional groups in the crosslinked $\mathrm{CMC}^{-\mathrm{SiO}_{2}}$ hydrogels.

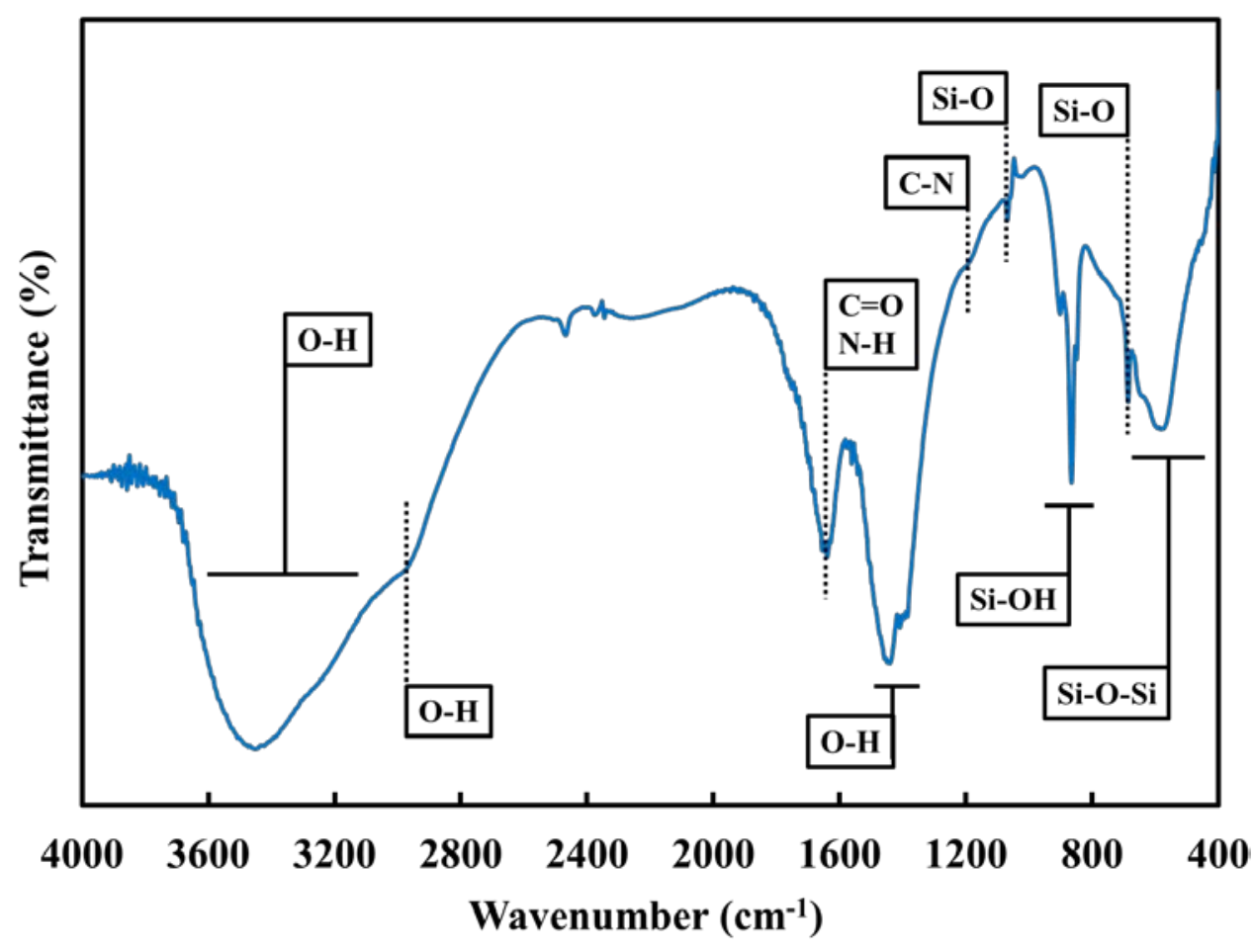

Source: own elaboration (2020)

In this process, the EDC allowed the formation of intermediates with the carboxyl groups in the CMC structure, such as the O-acylisourea (see Figure 4a), which is an unstable molecule. Then, the NHS was used to activate the carboxyl groups linked to the EDC molecules by displacing the O-acylisourea as isourea, promoting the formation of amine-reactive NHS ester (see Figure 4b) as another intermediate but more stable molecule.The activated carboxyl group was then able to interact with the primary amine group grafted on the surface of the $\mathrm{SiO}_{2}$ nanoparticles, completing the crosslinking of the CMC structure through the formation of secondary amides (see Figure 4c). Therefore, the successful crosslinking of CMC with the $\mathrm{SiO}_{2}$ nanoparticles was confirmed with the peak around $1640 \mathrm{~cm}^{-1}$, along with another one located between 1250 and $1020 \mathrm{~cm}^{-1}$ ascribed to C-N stretching vibrations(Asere et al., 2019).

On the other hand, the representative peaks of the $\mathrm{SiO}_{2}$ nanoparticles are evidenced in the wavenumber region of 1100 and $400 \mathrm{~cm}^{-1}$, which is attributed to the silanol (Si-OH) and siloxane (Si-O-Si) functional groups. The peaks around at 1069 and $687 \mathrm{~cm}^{-1}$ corresponded to the asymmetric and symmetric Si-O bonds for the $\mathrm{SiO}_{2}$ structure(Pourrajab, Noghrehabadi, Hajidavalloo, \& Behbahani, 2020), whereas the medium intensity and broadband between 650 and $450 \mathrm{~cm}^{-1}$ were attributed to the bending Si-O-Si vibration(Asri Mohd Esa \& Sapawe, 2020). An addition band was noted in the wavenumber region from 966 to $819 \mathrm{~cm}^{-1}$, which indicates remaining $\mathrm{Si}-\mathrm{OH}$ groups available on the large surface area of the $\mathrm{SiO}_{2^{-}}$ $\mathrm{NH}_{2}$ nanoparticles(Pourrajab et al., 2020). This represents a suitable surface for enhanced grafting with $\mathrm{NH}_{2}$ groups, providing a major crosslinking area for the interaction and binding with the carboxyl group from the CMC structure. 
Figure 4. Carbodiimide chemistry procedure for the crosslinking of CMC hydrogels and the incorporation of $\mathrm{SiO}_{2}$ nanoparticles.

a)
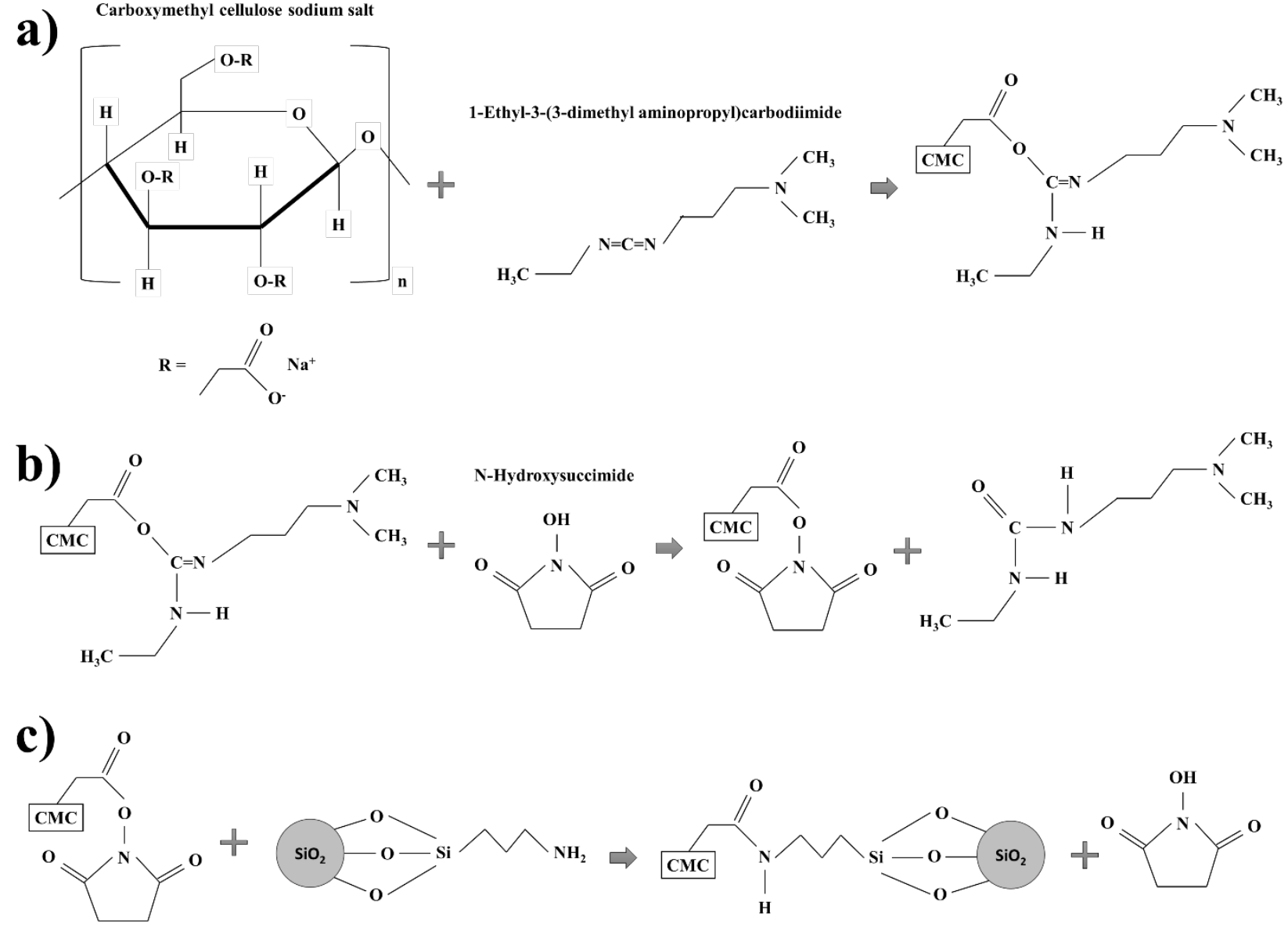

Source: own elaboration (2020)

The thermogravimetric analysis (TGA) and derivative thermogravimetric (DTG) curves are displayed in Figure 5 and Figure 6. The $\mathrm{CMC}$ was crosslinked using different concentrations of $\mathrm{SiO}_{2}-\mathrm{NH}_{2}$ nanoparticles to evaluate the thermal stability, considering as an important factor for applications in the biomedicine field. In Figure 5, the crosslinked CMC-SiO ${ }_{2}$ hydrogel using $0.1 \mathrm{~g}$ of $\mathrm{SiO}_{2}-\mathrm{NH}_{2}$ nanoparticles exhibited two main weight loss stages with several thermal events and maximum decomposition peaks. The three first event at 53,102 , and $164^{\circ} \mathrm{C}$ were mainly attributed to moisture or some water content in the crosslinked CMC- $\mathrm{SiO}_{2}$ hydrogel with a weight loss of about $27 \%$, in which water is evaporated at $164^{\circ} \mathrm{C}$ due to the strong binding between the $\mathrm{CMC}$ and $\mathrm{SiO}_{2}-\mathrm{NH}_{2}$ nanoparticles. Afterward, the weight was reduced up to $33 \%$ with a maximum decomposition at 250 and $279^{\circ} \mathrm{C}$ attributed to the release of $\mathrm{CO}_{2}$ from the carboxyl groups contained in the cellulose backbone(Jiang et al., 2016), which promote the cleavage and fragmentation of the main bonds in the structure(C. Zhang et al., 2020). However, two more events occurred at 352 and $430^{\circ} \mathrm{C}$,suggesting the decomposition of more stable organic content, which is related to the presence of $\mathrm{SiO}_{2}-\mathrm{NH}_{2}$ nanoparticles that provides higher thermal stability. 
Figure 5. Thermogravimetric analysis (TGA) and derivative thermogravimetric (DTG) curve of the hydrogels crosslinked with $0.1 \mathrm{~g}$ of $\mathrm{SiO}_{2}-\mathrm{NH}_{2}$ nanoparticles to determine changes in the sample weight over time as the temperature increases.

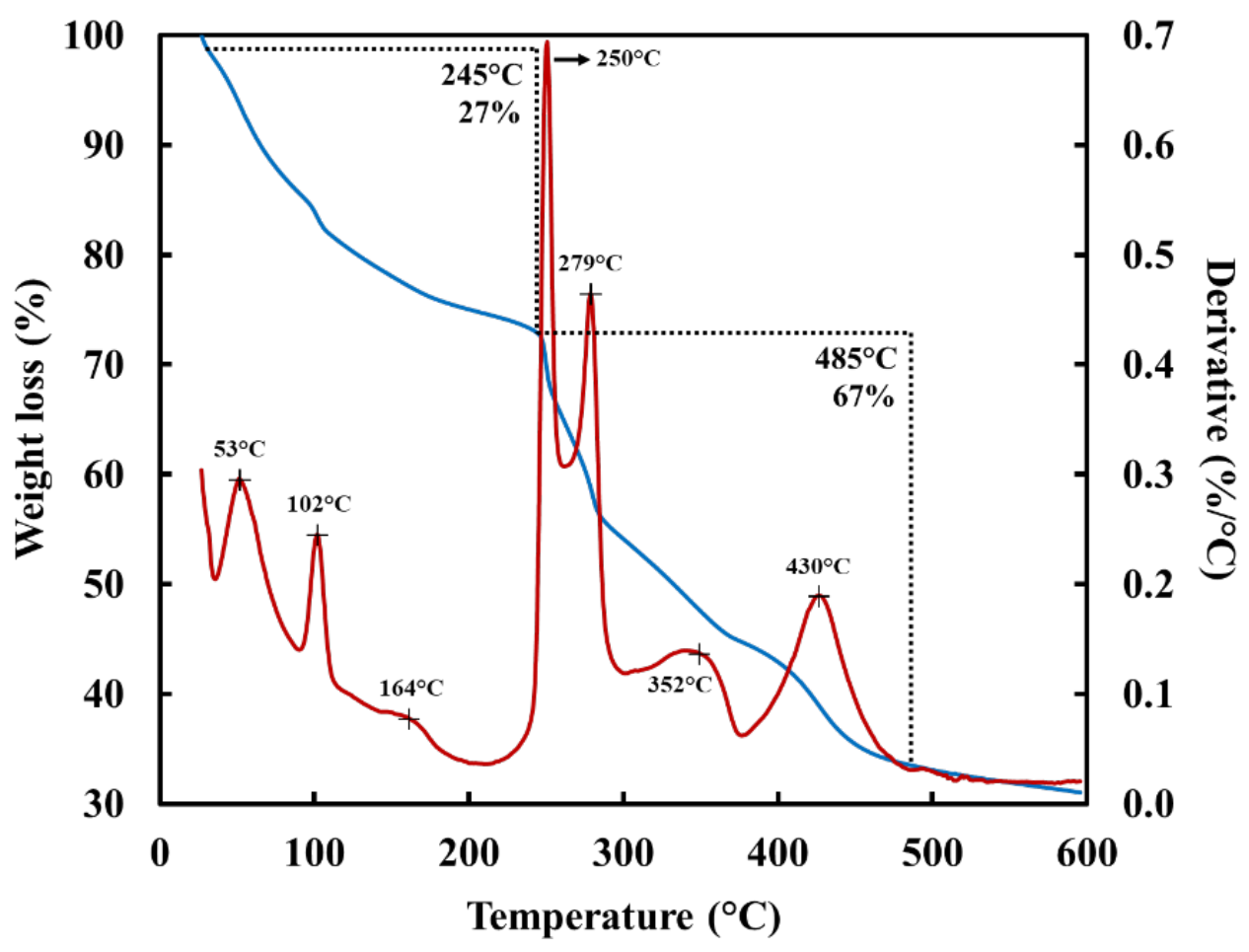

Source: own elaboration (2020)

In the case of the hydrogels crosslinked with $0.5 \mathrm{~g}$ of $\mathrm{SiO}_{2}-\mathrm{NH}_{2}$ nanoparticles shown in Figure 6, a twostage thermal decomposition was also observed. The decomposition events are reduced attribute to the presence of $\mathrm{SiO}_{2}-\mathrm{NH}_{2}$ nanoparticles, in which the evaporation of water content occurred up to $107^{\circ} \mathrm{C}$ instead of $164^{\circ} \mathrm{C}$ since the availability of $-\mathrm{OH}$ decreased due to the interaction with primary -NH groups. However, the weight loss was around $37 \%$ in this first stage, which was $10 \%$ more compared to the crosslinked $\mathrm{CMC}-\mathrm{SiO}_{2}$ hydrogel using $0.1 \mathrm{~g}$ of $\mathrm{SiO}_{2}-\mathrm{NH}_{2}$ nanoparticles. This effect is attributed to a major content of water that was adsorbed on the surface of the $\mathrm{SiO}_{2}-\mathrm{NH}_{2}$ nanoparticles, considering that the concentration was increased to $0.5 \mathrm{~g}$ which promotes a larger available surface area.In the second stage, the total number of decomposition events decreased, as well as the decomposition area, indicating major thermal stability in the crosslinked $\mathrm{CMC}-\mathrm{SiO}_{2}$ hydrogel structure. This is observed from the total remaining weight of $56 \%$ at $485^{\circ} \mathrm{C}$, in which the last thermal event $469^{\circ} \mathrm{C}$ related to the decomposition of more stable organic content, suggests an enhancement of about $30^{\circ} \mathrm{C}$ concerning the crosslinked hydrogels using $0.1 \mathrm{~g}$ of $\mathrm{SiO}_{2}-\mathrm{NH}_{2}$ nanoparticles.These two-stages decomposition results are highlighted in comparison with othersstudies in the literature for crosslinked CMC hydrogels using complex crosslinking agents, such as polyacrylamide (Jeong et al., 2020), ZnO nanoparticles (Gholamali \& Yadollahi, 2020), and $\mathrm{TiO}_{2}$ nanoparticles (Mahmoud et al., 2017) with a total remaining weight around 21, 30, and 60\%, respectively.Accordingly, the formation of amide covalent bonds using the carbodiimide crosslinker chemistry between the carboxylic acid from the CMC and the primary amine functional groups from the $\mathrm{SiO}_{2}-\mathrm{NH}_{2}$ nanoparticles, represent a more efficient alternative for the fabrication of hydrogelsby increasing the thermal stability up to $35 \%$. 
Figure 6. TGA and DTG curve of the hydrogels crosslinked with $0.5 \mathrm{~g}$ of $\mathrm{SiO}_{2}-\mathrm{NH}_{2}$ nanoparticles.

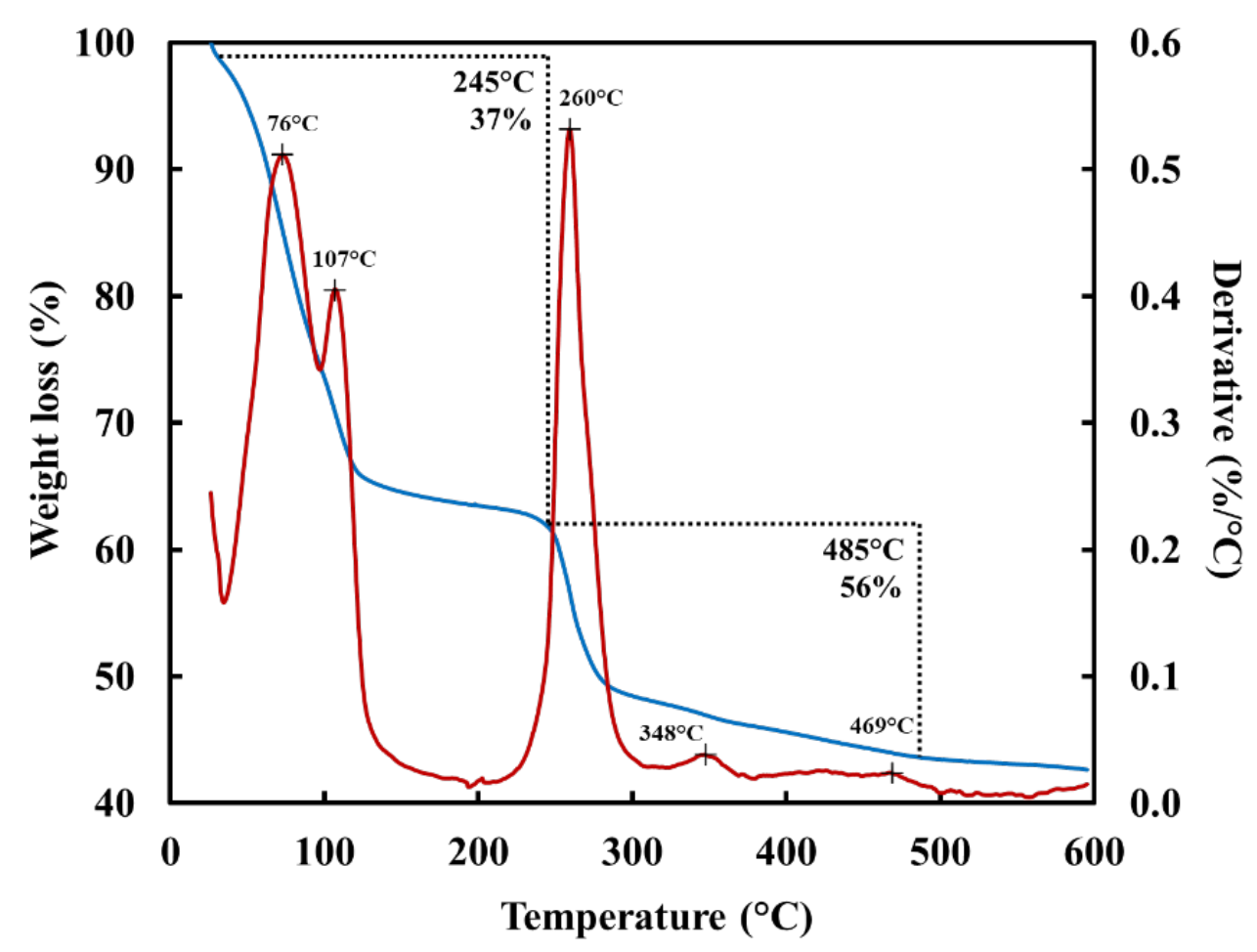

Source: own elaboration (2020)

\section{Conclusions}

This study reported the synthesis and amine-functionalization of $\mathrm{SiO}_{2}$ nanoparticles for the incorporation in crosslinked CMC hydrogels via the carbodiimide crosslinker chemistry. The material composition and thermal stability were deeply evaluated and analyzed, aiming to establish the potential application of the crosslinked $\mathrm{CMC}-\mathrm{SiO}_{2}$ hydrogels in controlled drug release and delivery systems. The primary $\mathrm{NH}_{2}$ groups grated on the surface of the $\mathrm{SiO} 2$ nanoparticles provided high affinity and strong interaction with the activated $\mathrm{C}=\mathrm{O}$ groups from the carboxylic acid in the $\mathrm{CMC}$ structure. This allowed the formation of stable amide bonds, which promoted enhanced thermal stability when increasing the temperature, as was observed in the DTG curves. Moreover, the content of $\mathrm{SiO}_{2}-\mathrm{NH}_{2}$ nanoparticles played an important role in the thermal stability of the CMC hydrogels, decreasing the percentage of decomposition and reducing the number of thermal events. According to these results, the crosslinked $\mathrm{CMC}-\mathrm{SiO}_{2}$ hydrogels showed to be a promising material compared to similar reported in the literature with lower thermal efficiencies.

Additional future research work involves a profound determination of the physicochemical properties, including chemical stability, drug loading and release capacities, swelling percentage, and the influence of 


\section{Crosslinked carboxymethyl cellulose-SiO2 hydrogels fabrication: Composition and thermal stability towards biomedical applications}

parameters such as $\mathrm{pH}$, temperature, and enzyme content on the efficiency of the controlled drug release systems.

\section{Acknowledgment}

The author is grateful to the Universidad de Cartagena (Colombia) for financial support in the development of this research project. Special thanks to Dr. Adriana Herrera for her academic and scientific assistance with the interpretation and discussion of the results.

\section{References}

Abeer, M. M., Rewatkar, P., Qu, Z., Talekar, M., Kleitz, F., Schmid, R.,... Popat, A. (2020). Silica nanoparticles: A promising platform for enhanced oral delivery of macromolecules. Journal of Controlled Release, 326(April), 544-555. https://doi.org/10.1016/j.jconrel.2020.07.021

Asere, T. G., Mincke, S., Folens, K., Vanden Bussche, F., Lapeire, L., Verbeken, K., ... Stevens, C. V. (2019). Dialdehyde carboxymethyl cellulose cross-linked chitosan for the recovery of palladium and platinum from aqueous solution. Reactive and Functional Polymers, 141(January), 145-154. https://doi.org/10.1016/j.reactfunctpolym.2019.05.008

Asri Mohd Esa, Y., \& Sapawe, N. (2020). Removal of methylene blue from aqueous solution using silica nanoparticle extracted from skewer coconut leaves. Materials Today: Proceedings, 31, 398-401. https://doi.org/10.1016/j.matpr.2020.07.192

Gholamali, I., \& Yadollahi, M. (2020). Doxorubicin-loaded carboxymethyl cellulose/Starch/ZnO nanocomposite hydrogel beads as an anticancer drug carrier agent. International Journal of Biological Macromolecules, $160,724-735$. https://doi.org/10.1016/j.ijbiomac.2020.05.232

Giner-Casares, J. J., Henriksen-Lacey, M., Coronado-Puchau, M., \& Liz-Marzán, L. M. (2016). Inorganic nanoparticles for biomedicine: Where materials scientists meet medical research. Materials Today, $19(1)$, 19-28. https://doi.org/10.1016/j.mattod.2015.07.004

Javanbakht, S., \& Shaabani, A. (2019). Carboxymethyl cellulose-based oral delivery systems. International Journal of Biological Macromolecules, 133, 21-29. https://doi.org/10.1016/j.ijbiomac.2019.04.079

Jeong, D., Kim, C., Kim, Y., \& Jung, S. (2020). Dual crosslinked carboxymethyl cellulose/polyacrylamide interpenetrating hydrogels with highly enhanced mechanical strength and superabsorbent properties. European Polymer Journal, 127(December 2019), 109586. https://doi.org/10.1016/j.eurpolymj.2020.109586

Jiang, X., Yang, Z., Peng, Y., Han, B., Li, Z., Li, X., \& Liu, W. (2016). Preparation, characterization and feasibility study of dialdehyde carboxymethyl cellulose as a novel crosslinking reagent. Carbohydrate Polymers, $137,632-641$. https://doi.org/10.1016/j.carbpol.2015.10.078

Kadry, G. (2019). Comparison between gelatin/carboxymethyl cellulose and gelatin/carboxymethyl nanocellulose in tramadol drug loaded capsule. Heliyon, 5(9), e02404. https://doi.org/10.1016/j.heliyon.2019.e02404

Kamel, S., El-Gendy, A. A., Hassan, M. A., El-Sakhawy, M., \& Kelnar, I. (2020). Carboxymethyl cellulose-hydrogel embedded with modified magnetite nanoparticles and porous carbon: Effective environmental adsorbent. Carbohydrate Polymers, 242(April). https://doi.org/10.1016/j.carbpol.2020.116402

Kanikireddy, V., Varaprasad, K., Jayaramudu, T., Karthikeyan, C., \& Sadiku, R. (2020). Carboxymethyl cellulose-based materials for infection control and wound healing: A review. International Journal of Biological Macromolecules, 164, 963975. https://doi.org/10.1016/j.ijbiomac.2020.07.160

IPSA SCIENTIA - Vol. 5 Nº $1-2020$ 


\section{Crosslinked carboxymethyl cellulose-SiO2 hydrogels fabrication: Composition and thermal stability towards biomedical applications}

Lee, K. I., Lin, J. W., Su, C. C., Fang, K. M., Yang, C. Y., Kuo, C. Y., ... Chen, Y. W. (2020). Silica nanoparticles induce caspase-dependent apoptosis through reactive oxygen species-activated endoplasmic reticulum stress pathway in neuronal cells. Toxicology in Vitro, 63(August 2019), 104739. https://doi.org/10.1016/j.tiv.2019.104739

Lin, P., Liu, L., He, G., Zhang, T., Yang, M., Cai, J., ... Tao, S. (2020). Preparation and properties of carboxymethyl chitosan/oxidized hydroxyethyl cellulose hydrogel. International Journal of Biological Macromolecules, 162(November 2020), 1692-1698. https://doi.org/10.1016/j.ijbiomac.2020.07.282

Mahmoodi, N. M., Khorramfar, S., \& Najafi, F. (2011). Amine-functionalized silica nanoparticle: Preparation, characterization and anionic dye removal ability. Desalination, 279(1-3), 61-68. https://doi.org/10.1016/j.desal.2011.05.059

Mahmoud, M. E., Abdou, A. E. H., Sobhy, M. E., \& Fekry, N. A. (2017). Solid-solid crosslinking of carboxymethyl cellulose nanolayer on titanium oxide nanoparticles as a novel biocomposite for efficient removal of toxic heavy metals from water. International Journal of Biological Macromolecules, 105(December 2017), 1269-1278. https://doi.org/10.1016/j.ijbiomac.2017.07.156

Mapkar, J. A., Iyer, G., \& Coleman, M. R. (2009). Functionalization of carbon nanofibers with elastomeric block copolymer using carbodiimide chemistry. Applied Surface Science, 255(9), 4806-4813. https://doi.org/10.1016/j.apsusc.2008.11.068

Pourrajab, R., Noghrehabadi, A., Hajidavalloo, E., \& Behbahani, M. (2020). Investigation of thermal conductivity of a new hybrid nanofluids based on mesoporous silica modified with copper nanoparticles: Synthesis, characterization and experimental study. Journal of Molecular Liquids, 300 (February 2020), 112337. https://doi.org/10.1016/j.molliq.2019.112337

Rao, Z., Ge, H., Liu, L., Zhu, C., Min, L., Liu, M., ... Li, D. (2018). Carboxymethyl cellulose modified graphene oxide as pHsensitive drug delivery system. International Journal of Biological Macromolecules, 107(PartA), 1184-1192. https://doi.org/10.1016/j.ijbiomac.2017.09.096

Sepulveda, J., Villegas, C., Torres, A., Vargas, E., Rodriguez, F., Baltazar, S., ... Galotto, M. J. (2020). Effect of functionalized silica nanoparticles on the mass transfer process in active PLA nanocomposite films obtained by supercritical impregnation for sustainable food packaging. Journal of Supercritical Fluids, 161(July), 104844. https://doi.org/10.1016/j.supflu.2020.104844

Shahbazi, M., Ahmadi, S. J., Seif, A., \& Rajabzadeh, G. (2016). Carboxymethyl cellulose film modification through surface photo-crosslinking and chemical crosslinking for food packaging applications. Food Hydrocolloids, 61(December), 378389. https://doi.org/10.1016/j.foodhyd.2016.04.021

Tang, J., Li, Y., Song, Y., Wu, X., Yu, G., \& Tam, K. C. (2020). Carbodiimide coupling versus click chemistry for nanoparticle surface functionalization: A comparative study for the encapsulation of sodium cholate by cellulose nanocrystals modified with $\beta$-cyclodextrin. Carbohydrate Polymers, 244(May), 116512. https://doi.org/10.1016/j.carbpol.2020.116512

Zhang, C., Yang, X., Li, Y., Qiao, C., Wang, S., Wang, X., ... Li, T. (2020). Enhancement of a zwitterionic chitosan derivative on mechanical properties and antibacterial activity of carboxymethyl cellulose-based films. International Journal of Biological Macromolecules, 159(September), 1197-1205. https://doi.org/10.1016/j.ijbiomac.2020.05.080

Zhang, Z., Zhu, Y., Dai, R., Zhang, Y., Wang, H., \& Li, J. (2018). Enhanced photocytotoxicity induced by a platinum diimine complex employing amine-functionalized magnetite-silica nanocomposites as delivery vehicles. Photodiagnosis and Photodynamic Therapy, 23(June), 50-54. https://doi.org/10.1016/j.pdpdt.2018.06.002

Zhong, Y., Wang, J., Yuan, Z., Wang, Y., Xi, Z., Li, L., ... Guo, X. (2019). A mussel-inspired carboxymethyl cellulose hydrogel with enhanced adhesiveness through enzymatic crosslinking. Colloids and Surfaces B: Biointerfaces, 179(December 2018), 462-469. https://doi.org/10.1016/j.colsurfb.2019.03.044 
Crosslinked carboxymethyl cellulose-SiO2 hydrogels fabrication: Composition and thermal stability towards biomedical applications

Zhu, X., Bao, L., Wei, Y., Ma, J., \& Kong, Y. (2016). Removal of toxic indigo blue with integrated biomaterials of sodium carboxymethyl cellulose and chitosan. International Journal of Biological Macromolecules, 91(October), 409-415. https://doi.org/10.1016/j.ijbiomac.2016.05.097 